\title{
El decadentismo modernista de Ventura García Calderón. Anomia, patologías y sátira en «Invitación a la soledad»
}

\section{The modernist Decadentism of Ventura García Calderón. Anomie, pathologies and satire in Invitación a la soledad}

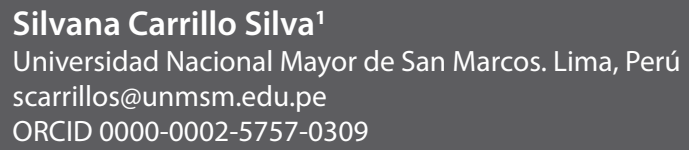

Citar como: Carrillo, S. (2019). El decadentismo modernista de Ventura García Calderón. Anomia, patologías y sátira en «Invitación a la soledad». Desde el Sur, 11(2), pp. 333-341.

\section{RESUMEN}

El siguiente artículo tiene como objetivo analizar el cuento «Invitación a la soledad» de Ventura García Calderón, publicado en el libro Color de Sangre de 1931. Este cuento es un ejemplo de cómo se manifiesta la estética decadentista modernista en la anomia social, las patologías mentales y orgánicas, y la sátira. Para dar cuenta de estos elementos se ha recurrido a la sociología de Émile Durkheim, la psicología analítica de Carl Gustav Jung y la teoría de los modos ficcionales de Northrop Frye.

\section{PALABRAS CLAVES}

Decadentismo modernista; Anomia; Patología; Arquetipo; Mito del Invierno

\section{ABSTRACT}

This paper aims to analyze the story «Invitación a la soledad» by Ventura García Calderón, published in the book Color de sangre, in 1931. The story is an example of how the modernist Decadentist aesthetic manifests itself in social

\footnotetext{
1 Bachiller en Literatura Peruana y Latinoamericana, y licenciada en Educación con mención en Lengua y Literatura de la Universidad Nacional Mayor de San Marcos. Se desarrolla dentro del campo de la edición de textos en diversas casas editoriales del país, como Norma, Santillana y Penguin Random House. En la actualidad, cursa estudios de maestría en Literatura Peruana y Latinoamericana en la misma casa de estudios y participa de cursos en el Instituto Eleusis - Psicología Analítica Junguiana Perú. Prepara su tesis de maestría con el título El arquetipo del puer aeternus en 1911, novela peruana de Ventura García Calderón.
} 
anomie, mental and organic pathologies, and satire. In our discussion of these elements, we employ the sociology of Émile Durkheim, the analytical psychology of Carl Gustav Jung, and the fictional modes theory of Northrop Frye.

\section{KEYWORDS}

Modernist Decadentism, anomie, pathology, archetype, Myth of Winter

El presente ensayo se concentra en el análisis del cuento «Invitación a la soledad», de Ventura García Calderón, publicado en el libro Color de sangre, de 1931. Gran parte de la obra de García Calderón ha merecido poca atención de parte de los lectores y la crítica literaria.

En esta oportunidad, deseamos hacer una nueva lectura mediante un enfoque que sea capaz de integrar los temas tratados en ella en la tradición literaria. En tal sentido, a partir de la contextualización de la obra de García Calderón en el llamado decadentismo modernista, estudiaremos cómo se representan y comunican la anomia social, las patologías mentales y orgánicas, y la sátira. Para lograr este objetivo, revisaremos los aportes de la sociología de Émile Durkheim, la psicología analítica de Carl Gustav Jung y la teoría de los modos ficcionales de Northrop Frye.

\section{Introducción}

Ventura García Calderón es uno de los autores más prolíficos de nuestro país. Sin embargo, gran parte de su obra es poco conocida entre el público lector y ha merecido pocos estudios de parte de la crítica literaria. Esta se ha encargado de estudiar su obra con un exceso de biografismo, así como un interés meramente sociológico, sobre todo su producción perteneciente al llamado exotismo regionalista. Contra este olvido y manera de estudiar su obra, nuestra investigación pretende mostrar la poca conocida producción decadentista modernista de García Calderón, como es el cuento «Invitación a la soledad», de su libro Color de sangre. Nuestra hipótesis sostiene que la obra de García Calderón pertenece al decadentismo modernista. Nuestro objetivo es contextualizar e integrar los temas abordados en el cuento por medio de la representación de la anomia social, las patologías mentales y orgánicas, y la sátira.

\section{El modernismo y el decadentismo en Ventura García Calderón}

En el Perú, el modernismo tuvo como primer representante a Manuel González Prada. En 1886, en uno de sus discursos en el Ateneo de Lima, exhortaba a los jóvenes poetas a buscar nuevos elementos en otras 
literaturas. Sus seguidores inmediatos fueron el arequipeño Jorge Polar y el limeño José Santos Chocano. Alrededor de este último se agruparon Clemente Palma, José Antonio Román, José Fiansón, Enrique Carrillo, entre otros. Sin embargo, a diferencia de Chocano, cuyo modernismo se impone desde las primeras líneas, sus seguidores se alinearon originalmente con el decadentismo, especialmente Román, a quien se le llegó a describir como el soñador de fantasías enfermas (Mostajo, 1896).

Una generación posterior, Ventura García Calderón, radicado en París desde su juventud, analizaba el papel del modernismo en el contexto de la literatura hispanoamericana. Para él, a diferencia de los anteriores movimientos literarios, como el romanticismo y el naturalismo, el modernismo tenía la ventaja de ser un producto cultural netamente latinoamericano. Por tal razón, consideraba que su aparición se contraponía a la literatura colonial, descrita por él como un «monótono panegírico», resultado de la violencia y la barbarie de la Conquista (Sumalavia, 2014, p. 274).

En cuanto intento de crear una literatura latinoamericana propia, el modernismo formaba parte de un proceso histórico y cultural de mayor envergadura. Así, a pesar de la superficialidad con la que los escritores latinoamericanos habrían asumido el aporte occidental, desde su punto de vista, el modernismo se habría constituido en el vehículo por el que la civilización latinoamericana podía visualizar su futuro a través de la imaginación (Sumalavia, 2014, p. 275).

Sin embargo, en el caso específico de García Calderón, el modernismo habría tomado una forma estética muy precisa: la decadencia. En efecto, los personajes de sus obras se encuentran inmersos en ambientes burgueses «saturados de sus propios vicios» y, al mismo tiempo, García Calderón trata de «exaltar la subjetividad del yo del artista» a partir del erotismo y del hedonismo (Sumalavia, 2014, p. 343).

En esta perspectiva, Jorge Valenzuela sostiene que la producción cuentística de García Calderón podría dividirse en dos etapas: el modernismo decadentista y el exotismo regionalista (Valenzuela Garcés, 2011, p. 9). Como se sabe, frente al modernismo, que tiende a revalorar el pasado clásico, García Calderón, influenciado por el decadentismo, sitúa su visión en el presente, especialmente cuando se trata de describir la descomposición moral de determinados ambientes y personajes. Al mismo tiempo, construye universos y sujetos exóticos debido a la distancia establecida entre el observador y el mundo observado. También aporta una renovación a nivel del lenguaje poético, en cuanto posee una visión cosmopolita de la lengua e incluyen léxicos provenientes de los más variados ámbitos sociales (Valenzuela Garcés, 2011, p. 19). 
En este sentido, el modernismo de García Calderón sería, como dice Valenzuela Garcés, «más una actitud o sensibilidad frente al mundo (un mundo en descomposición que ciertamente cuestiona), que un conjunto de principios establecidos por una escuela» estética. El combate contra el utilitarismo es fundamental para nuestro autor, que, desde dos frentes, ataca a la civilización materialista. Así, no solo valora el arte por sí mismo, sino que logra, con su ejercicio, mostrar la degradación de la burguesía de comienzos del siglo XX (2011, p. 21).

Su etapa de narrador modernista decadentista se extiende de 1914 a 1924, año en que publica La venganza del cóndor, y destacan especialmente dos obras: Dolorosa y desnuda realidad, publicada en 1914, y 1911: novela peruana, publicada tardíamente en 1941. La primera de ellas es un homenaje a los maestros decadentistas del siglo XIX: Baudelaire, Sade y Wilde. Se trata de una obra violenta y desgarradora llena de personajes decadentes y libertinos sexuales. La segunda retrata ciertos ámbitos de la alta burguesía limeña, sofocada por la hipocresía religiosa y la satisfacción de mezquindades personales (Valenzuela Garcés, 2011, p. 10).

La postura crítica de Ventura García Calderón frente a la vida superficial y llena de excesos de su época ha sido dilucidada en su etapa de modernismo decadentista. Sin embargo, este decadentismo no desaparece de su obra, sino que constituye el sustrato sobre el cual se va a construir el exotismo regionalista de su segunda etapa. En efecto, este regionalismo parece ser una continuidad del programa modernista en clave costumbrista. El cosmopolitismo universalista burgués desaparece $y$, en su lugar, aparece la búsqueda de un exotismo ctónico, ligado a la experiencia concreta de la tierra. Por esta razón, los temas mórbidos y violentos del decadentismo se potencian en el duro y complejo contexto americanista y peruano de su época. El sujeto exótico, construido a partir de lo extraño y misterioso, reaparece ahora bajo un nuevo ropaje: el indígena serrano o selvático, y la descripción de su condición degradada, en un nuevo ambiente: la sierra o la selva peruana (Valenzuela Garcés, 2011, p. 61).

\section{Anomia, patologías y sátira en «Invitación a la soledad»}

El cuento gira en torno a una historia narrada por un comerciante judío a un cónsul del Perú en Francia. Esta comienza cuando Gabriel Lanzade solicita los servicios de transporte de la casa Lévy Frères, donde trabaja Lazare Gutman, para viajar a la selva peruana con su joven amante.

Comolo ha resaltado Jorge Nájar(2011, p. 18), el cuento en un primermomento remite hacia «lo invisible»: la Primera Guerra Mundial y sus secuelas. El cuento se divide en dos segmentos. En el primero, el primer narrador se identifica como un cónsul que expone el contexto en el que se desenvuelve 
con sus conocidos: el judío Lazare Gutman y el chino Thaï-Suong. Nos encontramos en 1917 y asistimos a un ambiente en el que las normas morales han pasado a un segundo plano. El cuento se desarrolla en un pequeño bar de mala fama, cerca del puerto, donde, a partir de las diez de la noche, jóvenes soldados ebrios, que todavía no participan de la guerra, juegan disparando sus revólveres.

El cónsul realiza una analogía entre los lazos de su amigo chino con la prostitución clandestina y la participación de la joven mujer en la historia del amigo judío. Ambas aluden a situaciones fuera de la norma producidas por el caos de la sociedad. El judío Lazare Gutman no tenía simpatía por el chino Thaï-Suong, porque tenía fama de traficar mujeres para abastecer sus prostíbulos clandestinos en China. Al cónsul no parece importarle estas acciones, pues las califica como «fruslerías» y, en defensa del chino, sostiene que sería muy difícil, incluso durante el caos de la guerra, que un asiático transporte mujerzuelas hacia el puerto. Nos vemos así en un ambiente anómico tal como Durkheim ha descrito. Según él, la anomia es un estado de la sociedad en el que las normas jurídicas y morales desaparecen. Su causa principal es la falta de regulación normativa en la esfera económica de las sociedades modernas (Durkheim, 1967, p. 312).

Entrando al segundo segmento del cuento, el judío inicia la narración de la historia del viaje de la singular pareja. Como narrador testigo de los hechos, para el judío Lazare Gutman, Gabriel (el personaje principal de su historia) sería una combinación del héroe decadentista: pasa de ser un dandy estoico a un neurótico lánguido. Primero, lo describe como un hombre joven que hace pasar a su amante por su esposa para viajar juntos a la selva virgen y como un deportista en busca de emociones antes de llegar a los 50 años. Pero, durante el viaje, Lazare gradualmente descompone la imagen que tenía de Gabriel al inicio. Por ejemplo: el judío queda impresionado al enterarse de que a Gabriel no le agradaba dejar Europa y, ante su insistencia por saber por qué quería ir a la selva sin pretender ser un aventurero, Gabriel no responde y permanece pensativo.

Cuando observan «la diversión clásica del barco», ver cómo los tiburones devoran los desechos que los cocineros les arrojan, Gabriel se muestra ensimismado y lanza una pregunta al aire: ¿cree usted que uno muere inmediatamente? El judío tarda en entender la referencia y responde con una broma. Esta referencia a un posible suicidio hace que Lazare observe y reflexione sobre el aspecto físico y la salud mental de Gabriel. La palidez de su rostro, los ojos enrojecidos, la fatiga, el ensimismamiento y una sospechosa mancha de color rosado amarillento en la frente. Lo califica como un neurasténico más. Para el judío, cualquiera puede ser un neurasténico, pues todo el mundo puede sentir el deseo de hundirse en el mar, hasta 
que se dan cuenta de que el mar es demasiado frío y los tiburones son criaturas horribles.

Según Durkheim, la neurastenia constituye un estado intermedio entre la alienación mental y el equilibrio psicológico. A pesar de no ser la causa directa de la conducta suicida, la neurastenia, en cuanto patología, constituye un elemento capaz de predisponer a tal conducta. Una de sus características más conocidas es el dolor que parece ser el resultado de una debilidad generalizada del sistema nervioso. En este sentido, para el neurasténico, toda impresión es una causa de malestar; todo movimiento, una fatiga; incluso las funciones fisiológicas constituyen una fuente de molestia para él. Por la misma razón, el neurasténico posee una sensibilidad mayor para el placer, puesto que la debilidad del sistema nervioso permite el acceso a excitaciones que un organismo normal sería incapaz de experimentar (Durkheim, 1928, p. 33).

Llegamos al clímax del cuento, el judío y sus remeros se disponen a partir y presencian una discusión entre la pareja. La joven mujer huye corriendo de Gabriel, mientras este la persigue desesperado. Nos enteramos de que Gabriel padece de lepra y su viaje se debe a un acto desesperado de amor. Su intención era aislarse en la selva virgen y vivir su enfermedad con la mujer que ama, sin que ella lo supiese y sea tarde para que pueda regresar.

Al final, Gutman es intimidado por Gabriel y este y sus hombres abandonan a la pareja en el campamento de lujo que habían instalado. Gutman reflexiona sobre la lepra y recuerda el modo en que esa enfermedad ha sido afrontada por la humanidad. Los leprosos eran trasladados en barcos a zonas desérticas para vivir y morir en paz.

Detrás de la narración de García Calderón, podemos descubrir una dimensión mitológica que tiene en la acción del rapto su principal ejemplo. Como se conoce, el tema del rapto está presente en varias mitologías de la antigüedad, como la de Isis y Osiris, Tammus y Adonis, Dionisos y Zeus, Deméter y Perséfone, entre otros. La idea común a estos mitos es el sacrificio y la resurrección de una divinidad joven, gracias a cuya muerte se instituye el ciclo natural de las estaciones. En el mito, la diosa madre o el dios padre, que reina en el mundo celeste, ofrece a su hijo o hija a las fuerzas infernales; estas lo devoran y, luego de ser transformado, resucita con nuevos atributos.

En el cuento, el drama mítico está constituido por Gabriel, la joven amante y la selva virgen; aunque la referencia a una figura materna o paterna está ausente. Como vemos, desde el inicio el mito está incompleto, puesto que en él la figura de la madre-padre es fundamental. Esta ausencia no solo aparece en la figura de la joven amante, sino que también se manifiesta en las prostitutas raptadas del amigo chino Thaï-Suong. 
La imagen de una joven desconocida sometida al rapto reproduce fielmente aquello que Jung identifica con la figura de la Core. La Core es la doncella que, en los mitos, suele estar expuesta a toda clase de peligros, como ser devorada por monstruos o ser sacrificada ritualmente como víctima. La doncella experimenta así un viaje al Hades del que eventualmente sale transformada (Jung, 2004, p. 189).

Sin embargo, en el cuento no existe tal transformación, pues la joven amante no solo se opone a su destino, sino que incluso su voz se funde con los sonidos de la selva al final de la narración del judío. En este sentido, nos encontramos frente al arquetipo del ánima, puesto que la doncella abandonada constituye una de sus figuras. El ánima presente en el cuento de García Calderón está condenada a vivir en lo inconsciente colectivo, es decir, a desaparecer en la selva virgen, sin posibilidad de acceder a la conciencia (Jung, 2004, p. 188).

Sin embargo, el drama mítico no se agota ahí, puesto que esta fusionado con otro mitologema bastante conocido, aunque proveniente de otra tradición cultural. Nos referimos a la presencia simbólica de la enfermedad bíblica por antonomasia: la lepra. No es casual que García Calderón haya creado un personaje judío de nombre Lazare (en español, Lázaro), puesto que, hasta aquella época, la lepra era descrita como el mal de San Lázaro. En este nombre, se fusionan la imagen de aquel muerto que Jesús revivió con la condición infrahumana de este personaje.

Como se sabe, la lepra ha jugado un rol fundamental en la vida del pueblo judío, al punto que simboliza la condición de impureza frente a Dios. En el Levítico, Yahvé castiga a la mujer de Aaron con la lepra por su maledicencia contra Moisés, entre otros ejemplos. Del mismo modo, en el cuento, el judío reconoce tardíamente en la mancha de Gabriel la enfermedad impura y, al final, rememora el trato que recibían los condenados por esta enfermedad.

¿Qué relación hay entre ambos discursos míticos? Tanto el Hades como la lepra son imágenes asociadas a lo demoniaco. Sin embargo, mientras el Hades o la selva del cuento es una condición natural, la lepra no solo es una enfermedad, sino una condición espiritual. De esta manera, Gabriel no solo representa al Hades violador, sino que encarna el mal en sí mismo al estar manchado con la ominosa enfermedad. Además de ellos, al haber planificado «esta invitación a la soledad», ha elegido libremente su opción por la perversión del amor.

Estos elementos míticos nos permiten contextualizar el cuento en aquello que Northrop Frye ha llamado mito del invierno. Según Frye, las narraciones que pueden situarse en esta clasificación pertenecen al modo 
ficcional de la ironía, sea esta trágica o cómica. En el caso del cuento de García Calderón, nos enfrentamos a un tipo de ironía cómica, puesto que el personaje principal Gabriel, no solo es inferior moralmente al lector de la obra, sino que todos los personajes de ella participan de la misma miseria espiritual. Sin embargo, en el cuento, el personaje principal queda aislado de su entorno, razón por la cual la narración también formaría parte del modo ficcional irónico trágico.

Esta curiosa combinación de tragedia y comedia al interior de la ironía es posible porque García Calderón narra una misma historia dos veces. En efecto, por un lado, conocemos la narración del cónsul y, por otro, la del judío Lazare, las cuales constituyen una misma historia. La posibilidad de ir de un extremo a otro de la ironía configura el contenido de una sátira demencial, en donde los aspectos demoniacos son resaltados constantemente (Frye, 1991, pp. 293-294).

A diferencia del profesor Valenzuela, para quien García Calderón es, ante todo, un modernista decadentista ligado a la herencia de Darío y Rodó, pensamos que la impronta de la cultura francesa en su obra ha sido mucho más importante. En realidad, García Calderón es, en principio, un autor afín al decadentismo que, de manera coyuntural entronca con el modernismo, del mismo modo como lo hace con el exotismo regionalista que caracterizó la segunda etapa de su obra. Seguramente, esta impronta decadentista ha hecho que Juan Carlos Ubilluz (2017, p. 84) vea en García Calderón más a un seguidor de Calibán que de Ariel. Sin embargo, la analogía se queda corta, pues aquello que precisamente caracterizó al decadentismo fue una espiritualidad visceral que, lejos de negar la inteligencia y los valores trascendentes, los exacerbó, pero en clave negativa e, incluso, satánica. En tal sentido, vemos, en García Calderón, escritor decadentista, una unión perfecta de aquello que Rodó había separado: Ariel y Calibán, la carne y el espíritu. Así, nos enfrentamos a un escritor decadentista francés que escribe en castellano en el contexto de la expansión del modernismo latinoamericano literario. Por tal razón, Ventura García Calderón debe ser considerado un escritor adscrito al decadentismo modernista.

\section{Contribuciones}

Silvana Carrillo Silva ha participado en la concepción del artículo, en la recolección de datos, y en la redacción y aprobación de la versión final.

\section{Fuente de financiamiento}

Autofinanciado.

\section{Conflictos de interés}

La autora declara no tener conflicto de interés. 


\section{REFERENCIAS BIBLIOGRÁFICAS}

Durkheim, E. (1928). El suicidio. Estudio de sociología. Madrid: Reus.

Durkheim, E. (1967). De la división del trabajo social. Buenos Aires: Schapire.

Frye, N. (1991). Anatomía de la crítica. Caracas: Monte Ávila Editores.

García Calderón, V. (2011). Narrativa completa. Tomo I y ll. Lima: Fondo Editorial de la Pontificia Universidad Católica del Perú.

Jung, C. G. y Kerényi, K. (2004). Acerca del aspecto de la figura de la Core. En C. G. Jung y K. Kerényi. Introducción a la esencia de la mitología. Madrid: Siruela.

Mostajo, F. (1896). Los modernistas peruanos. La Neblina, 12, 13, 14.

Nájar, J. (2011). La narrativa francesa de Ventura García Calderón: tapices flamencos por el revés. En R. Silva-Santisteban (Ed.). Ventura García Calderón. Narrativa completa II (pp. 7-34). Lima: Fondo Editorial de la Pontificia Universidad Católica del Perú.

Sumalavia, R. (2014). La prose moderniste péruvienne et la vision de la modernité chez Manuel González Prada, Clemente Palma et Ventura García Calderón (tesis de doctorado). Université Michel de Montaigne-Bordeaux III, Bordeaux. Recuperado de https://tel.archives-ouvertes.fr/tel-01142505

Ubilluz, J. C. (2017). La venganza del indio. Ensayos de interpretación por lo real en la narrativa indigenista peruana. Lima: Fondo de Cultura Económica.

Valenzuela Garcés, J. (2011). La experiencia narrativa de Ventura García Calderón: del decadentismo modernista a la cuentística del exotismo regionalista. En R. Silva-Santisteban (Ed.). Ventura García Calderón. Narrativa completa I (pp. 9-61). Lima: Fondo Editorla de la Pontificia Universidad Católica del Perú. 